Check for updates

Cite this: RSC Adv., 2019, 9, 21070

\title{
Unlocking high capacities of graphite anodes for potassium-ion batteries $\dagger$
}

\author{
Marco Carboni, (D)* Andrew J. Naylor, (D) Mario Valvo (D) and Reza Younesi (D)*
}

Graphite is considered a promising candidate as the anode for potassium-ion batteries (KIBs). Here, we demonstrate a significant improvement in performance through the ball-milling of graphite. Electrochemical techniques show reversible $\mathrm{K}$-intercalation into graphitic layers, with $65 \%$ capacity retention after 100 cycles from initial capacities and extended cycling beyond 200 cycles. Such an affinity of the graphite towards storage of $\mathrm{K}$-ions is explained by means of SEM and Raman analyses. Graphite ball-milling results in a gentle mechanical exfoliation of the graphene layers and simultaneous defect formation, leading to enhanced electrochemical performance.

Received 13th March 2019

Accepted 28th June 2019

DOI: 10.1039/c9ra01931f

rsc.li/rsc-advances and experimental studies has revealed that the reversible sequence $\mathrm{C}-\mathrm{KC}_{36}-\mathrm{KC}_{24}-\mathrm{KC}_{8}$ is the stage pathway followed by $\mathrm{K}$ GICs during discharge/charge processes., ${ }^{5,11}$ Experimental values of 273 and $244 \mathrm{~mA} \mathrm{~h} \mathrm{~g}^{-1}$ after the first discharge (potassium insertion) $)^{4,5}$ are in good agreement for the theoretical specific capacity for $\mathrm{KC}_{8}$ of $279 \mathrm{~mA} \mathrm{~h} \mathrm{~g}^{-1}$. Unfortunately, many graphite-based electrodes suffer from low capacity retention on extended cycling. A large volume expansion during the insertion of potassium has been claimed to be the main cause of the capacity drop, ${ }^{4,5}$ although the choices of cell configuration, binders, separators and electrolytes are also critical to prolong the lifetime of these cells., ${ }^{4,12}$

Here we report the substantial gains in electrochemical performance achieved by using ball-milled graphite as an anode for KIBs. The physical properties of the graphite are evaluated using scanning electron microscopy (SEM) and Raman spectroscopy, while electrochemical techniques are used to determine cycling performance and to shed light on potassium insertion mechanisms and solid electrolyte interphase (SEI) stability.

\section{Experimental methods}

\subsection{Materials and electrode preparation}

Electrodes were prepared from commercially available graphite by two different methods for testing as anodes for potassiumion batteries. In the first one, $0.200 \mathrm{~g}$ of commercial graphite powder (SLP-30, Timcal SA) and a $10 \%$ solution of polyvinylidene fluoride (PVDF, Arkema Kynar® FLEX 2801) in $N$ methyl-2-pyrrolidone (NMP, Sigma Aldrich) were mixed with a graphite : PVDF ratio of $9: 1 \mathrm{w} / \mathrm{w}$ using an agate mortar and pestle for 30 minutes. The resulting slurry was cast onto a copper foil current collector. The electrode was dried in a ventilated oven at $100{ }^{\circ} \mathrm{C}$ for $1 \mathrm{~h}$ and subsequently punched into $10 \mathrm{~mm}$-diameter discs. Before cell assembly, these pristine
Department of Chemistry - Angström Laboratory, Uppsala University, Box 538, SE-75121, Uppsala, Sweden. E-mail: reza.younesi@kemi.uu.se

$\dagger$ Electronic supplementary information (ESI) available. See DOI: 10.1039/c9ra01931f 
graphite (PG) electrodes were further dried at $120{ }^{\circ} \mathrm{C}$ under vacuum for $12 \mathrm{~h}$. For the second preparation method, the same materials, weight and weight ratios were adopted and placed in a $60 \mathrm{ml}$ zirconia jar together with two balls $(\varnothing=20 \mathrm{~mm}$, average weight $=25.55 \mathrm{~g}$ each) made by the same material. The graphite and PVDF solution was thoroughly mixed by ball-milling (i.e. ball-milled graphite - BMG) for $1 \mathrm{~h}$ at $150 \mathrm{rpm}$ in air, using a RETSCH PM 4 planetary ball mill. The resulting slurry was cast on a copper foil and cut and dried as described above. The active material mass loading was $1.40 \pm 0.13 \mathrm{mg} \mathrm{cm}{ }^{-2}$ for both types of electrode.

Counter and reference electrodes were prepared by pressing a piece of metallic potassium (Sigma Aldrich) onto a copper foil in an argon-filled glove box $\left(\mathrm{H}_{2} \mathrm{O}\right.$ and $\left.\mathrm{O}_{2}<1 \mathrm{ppm}\right)$. The $\mathrm{Cu}$ foil with the pressed potassium was then cut into discs with a diameter of $13 \mathrm{~mm}$.

The electrolyte was prepared by dissolving potassium hexafluorophosphate $\left(\mathrm{KPF}_{6}\right.$, Sigma Aldrich) in a mixture of $1: 1 \mathrm{v} / \mathrm{v}$ ethylene carbonate and diethyl carbonate (EC and DEC respectively, Sigma Aldrich) to obtain a $0.8 \mathrm{M}$ concentration. Prior to electrolyte preparation, $\mathrm{KPF}_{6}$ was dried overnight under vacuum at $120^{\circ} \mathrm{C}$, while the EC : DEC mixture was used after drying/storage on regenerated $3 \AA$ molecular sieves (Sigma Aldrich) for at least 15 days in a argon-filled glovebox $\left(\mathrm{H}_{2} \mathrm{O}\right.$ and $\left.\mathrm{O}_{2}<1 \mathrm{ppm}\right)$.

\subsection{Cell assembly}

Half-cells were assembled in rectangular polymer-coated aluminium pouches $(10 \times 12 \mathrm{~cm})$ using either the pristine graphite (PG) or ball-milled graphite (BMG) as working electrode and metallic potassium on copper $(\mathrm{Cu} / \mathrm{K})$ as combined reference and counter-electrode. A Solupor ${ }^{\circledR}$ 3P07A separator with the thickness of $20 \mu \mathrm{m}$ and porosity of $83 \%$ was cut into $\varnothing$ $=15 \mathrm{~mm}$ disc, placed between the electrodes in a pouch and then wetted with $0.1 \mathrm{~mL}$ of electrolyte using a micro fixed volume pipette. The pouches were finally sealed reducing the pressure down to 20 mbar. Symmetrical cells and threeelectrode cells were also assembled in the same way, by replacing graphite with a $\mathrm{Cu} / \mathrm{K}$ electrode and using another $\mathrm{Cu}$ / $\mathrm{K}$ electrode as reference, respectively.

\subsection{Electrochemical measurements}

Cyclic voltammetry (CV) was carried out with a half-cell configuration using a VMP3 (Bio-Logic) potentiostat, by applying a scan rate of $0.1 \mathrm{mV} \mathrm{s}^{-1}$ and a potential cut-off of 0.01 and $1.80 \mathrm{~V} v s . \mathrm{K}^{+} / \mathrm{K}$. Galvanostatic cycling was performed with the same equipment for the three-electrode cell tests, at two different specific current densities, 25 and $250 \mathrm{~mA} \mathrm{~g}^{-1}$, with a voltage cut-off of 0.01 and $1.50 \mathrm{~V} v s . \mathrm{K}^{+} / \mathrm{K}$. Half-cells and symmetrical cells were cycled using an Arbin battery cycler with rates of $25 \mathrm{~mA} \mathrm{~g}^{-1}$ and $0.1 \mathrm{~mA} \mathrm{~cm}^{-2}$, respectively. The voltage limitations for the half-cells were 0.01 and $1.50 \mathrm{~V} v s . \mathrm{K}^{+} / \mathrm{K}$, while the capacity limitation for the symmetric cells was $0.5 \mathrm{~mA} \mathrm{~h} \mathrm{~cm}^{-2}$. Pause tests ${ }^{\mathbf{1 3}, \mathbf{1 4}}$ were also performed on the halfcells, alternating galvanostatic cycles (at $25 \mathrm{~mA} \mathrm{~g}^{-1}$ ) with three extended pauses (OCV periods) for 4, 8 and 4 days, respectively.

\subsection{Electrode characterisation}

Raman spectroscopy was performed on a Renishaw inVia Raman microscope using an excitation wavelength of $532 \mathrm{~nm}$ from a laser diode with a maximum power of $500 \mathrm{~mW}$. The laser beam was focused on the surface of the as-prepared graphite electrode specimens via a $50 \times$ magnification objective. A constant laser power nominally corresponding to $0.5 \%$ of its maximum value was utilized for the analyses. A preliminary calibration of the spectrometer was performed by means of a $\mathrm{Si}$ wafer to obtain a characteristic reference peak at $520.6 \mathrm{~cm}^{-1} .40$ cumulative acquisitions with a measuring time of $20 \mathrm{~s}$ were run for each spectrum between $200 \mathrm{~cm}^{-1}$ and $3200 \mathrm{~cm}^{-1}$. The exposure to the laser beam was minimized in between subsequent measurements to avoid any possible degradation of the sample surface.

The surface morphologies of the as-prepared electrodes were investigated by means of a Field Emission Scanning Electron Microscope (FE-SEM, Zeiss LEO1550) via a dedicated In-Lens secondary electron detector and employing magnifications of $1000 \times$ and $20000 \times$ with an operation voltage of $10 \mathrm{keV}$. The cast electrode samples were mounted on aluminium stubs using double-sided adhesive conductive copper tape.

\section{Results and discussion}

The morphological and vibrational features of electrodes of pristine graphite (PG) and ball-milled graphite (BMG) are presented in Fig. 1. SEM images of PG particles in Fig. 1a and b display large and uneven particles with a wide particle size distribution ranging from a few micrometres to $30-40 \mu \mathrm{m}$. At high magnification (Fig. 1b), it is possible to observe the compact structure of the graphite particles, and even signs of the layered arrangement. The mild ball-milling process mainly induces two different effects as determined from Fig. 1c and d. The size of the graphite particles is reduced to about $20-25 \mu \mathrm{m}$, and it is clear that the ball-milling results in the formation of a more defective particle surface, which appears very uneven compared with the pristine particles.

Raman spectroscopy spectra of both PG and BMG electrodes are show in Fig. 1e. The spectrum of the PG electrode presents typical features of defective graphitic carbons, namely two main peaks at 1355 and $1580 \mathrm{~cm}^{-1}$, or so-called D and G bands, respectively. ${ }^{13,14}$ The $\mathrm{G}$ band is related to first order Raman signal of $\mathrm{sp}^{2}$-hybridized carbon species and this vibration mode has $\mathrm{E}_{2 \mathrm{~g}}$ symmetry involving in-plane bond-stretching movement of all pairs of $\mathrm{C}$ atoms with $\mathrm{sp}^{2}$ hybridization in both rings and chains. ${ }^{\mathbf{1 4}, 15}$ The interpretation of the $\mathrm{D}$ band is less straightforward and, although it is ascribed to the $\mathrm{A}_{1 \mathrm{~g}}$ breathing mode of $\mathrm{sp}^{2} \mathrm{C}$ atoms, understanding of its features results complex according to solid-state theory. ${ }^{14}$ This $\mathrm{A}_{1 \mathrm{~g}}$ mode is forbidden in perfect graphite and activates only in presence of disorder. ${ }^{15,16}$ The intensity ratio of the $\mathrm{G}$ and $\mathrm{D}$ bands (i.e. $I_{\mathrm{G}} / I_{\mathrm{D}}$ ) ties well with the degree of disorder here due to edge defects in the graphitic framework. ${ }^{16}$ The ' $2 \mathrm{D}$ ' band at $\sim 2700 \mathrm{~cm}^{-1}$ refers to the second order excitation of the $\mathrm{D}$ peak and consists of a main component at $\sim 2720 \mathrm{~cm}^{-1}$ and a shoulder at lower wavenumbers, with roughly $1 / 2$ and $1 / 4$ of the intensity of the $G$ peak, 

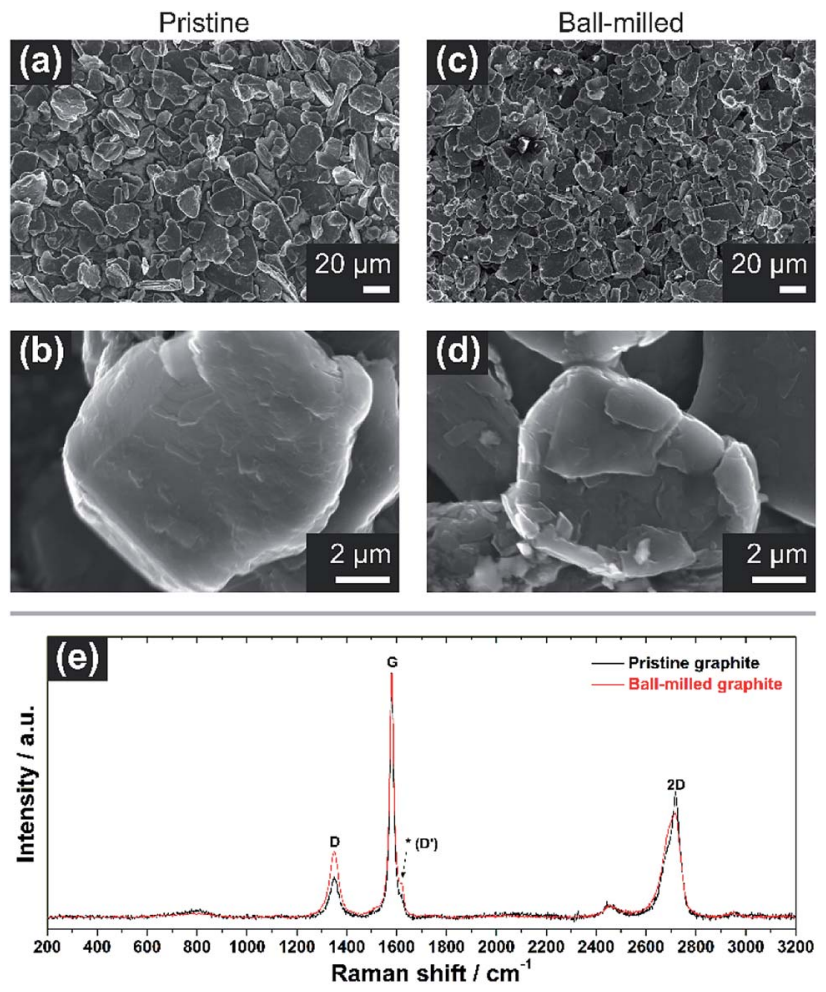

Fig. 1 (a and b) SEM images of the pristine graphite (PG) electrode at low $(1000 \times)$ and high $(20000 \times)$ magnification. (c and d) SEM micrographs of ball-milled graphite (BMG) electrode at low and high magnification. (e) Normalized Raman spectra of pristine (black) and ball-milled graphite (red). Note the increase of the relative intensity of the ' $D$ ' band in (e) after ball-milling, as well as a more prominent signal at $\sim 1620 \mathrm{~cm}^{-1}$ (see asterisk).

respectively. ${ }^{\mathbf{1 4 , 1 6 , 1 7}}$ The simultaneous presence of these two components confirms the existence of multi-layered graphitic frameworks. The spectrum of the BMG electrode displays the same peaks of PG, however, their relative intensities are visibly changed. In particular, the decreasing $I_{\mathrm{G}} / I_{\mathrm{D}}$ ratio highlights an increment of defects in the graphite particles, induced by the size reduction of the graphitic domains due to the ball-milling (see ESI $\dagger$ ). Another feature becomes also more pronounced after ball-milling around $\sim 1620 \mathrm{~cm}^{-1}$. The latter is often referred to as $\mathrm{D}^{\prime}$ peak and is characteristic of defected graphite. ${ }^{14}$ Furthermore, a broader shoulder of the band at $\sim 2700 \mathrm{~cm}^{-1}$ confirms a soft exfoliation of the graphite, without completely isolating the graphene layers from the main carbon domains, which is in agreement with the SEM analysis.

The electrochemical performance of graphite electrodes is evaluated here using half-cell configurations with potassium metal as the counter electrode. A symmetrical cell using potassium metal as both electrodes was used to demonstrate that the plating-stripping of potassium experiences an overpotential of approximately $\pm 0.1 \mathrm{~V}$ for the first $10-15$ cycles $(150$ $\mathrm{h}$ ), after which the polarization gradually increases to about $\pm 0.2 \mathrm{~V}$ (Fig. S1 $\dagger$ ). This demonstrates that potassium metal electrodes provide a reasonably low and acceptable polarization, thus it can be used as the counter electrode in half-cells. This is an interesting finding compared to lithium and sodium metals which have shown to be unsuitable counter electrodes because of their low efficiencies and high overpotentials, influencing the electrochemical performance of working electrodes. ${ }^{\mathbf{1 8 - 2 1}}$ Furthermore, the BMG electrode tested in three-electrode cells with potassium metal as both counter and reference electrodes shows suitable stability of the counter electrode especially at low rates (Fig. S2 $\dagger$ ). The electrochemical performance of the as-received graphite, cast as an electrode, is presented in Fig. 2. The PG electrode offers a specific capacity of $285 \mathrm{~mA} \mathrm{~h} \mathrm{~g}^{-1}$ during the first discharge (potassium insertion) and a poor reversible capacity of $115 \mathrm{~mA} \mathrm{~h} \mathrm{~g} \mathrm{~g}^{-1}$ upon charging (potassium extraction). Subsequent cycling leads to extensive capacity fade, with cell failure after only 25 cycles. Nevertheless, the coulombic efficiency ( $\mathrm{CE},\left[C_{\mathrm{ch}} / C_{\mathrm{dis}}\right] \times 100 \%$ ), only $41 \%$ for the first cycle, increases upon cycling, while remaining still far from previously reported efficiencies of $\geq 95 \% .{ }^{10}$ Four voltage plateaux are visible (Fig. 2b) on the first discharge at approximately $0.75,0.45,0.25$ and $0.1 \mathrm{~V}$, which are more easily observed in the $\mathrm{d} Q / \mathrm{d} V$ plot in Fig. 2c as definitive peaks. The peaks at higher voltages are visible only on the first cycle and are ascribed to SEI formation, while the lower voltage features are assigned to potassium insertion into graphite.

Compared with the PG electrode, the BMG electrode shows significantly improved electrochemical performance at the same applied current density (see Fig. 3a). The BMG exhibits an initial discharge capacity of $345 \mathrm{~mA} \mathrm{~h} \mathrm{~g}^{-1}$, and charge
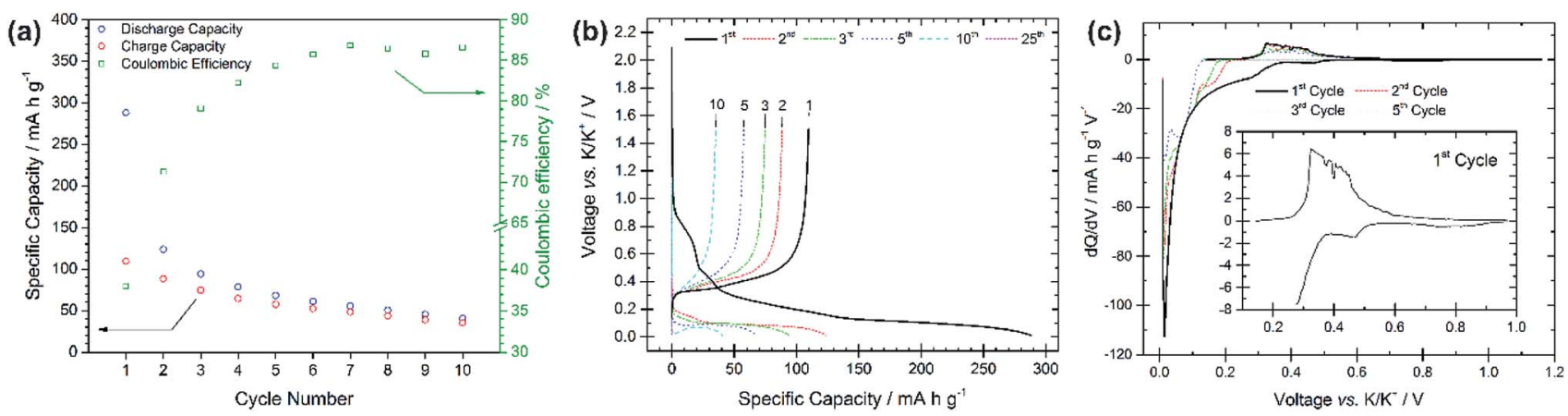

Fig. 2 (a) Specific capacity vs. cycle number for the pristine graphite electrode galvanostatically cycled at $25 \mathrm{~mA} \mathrm{~g} \mathrm{~g}^{-1}$ with potential limitations of $0.01 \mathrm{~V}$ and $1.5 \mathrm{~V} v \mathrm{v}$. $\mathrm{K} / \mathrm{K}^{+}$. (b) Voltage profiles $\mathrm{vs}$. specific capacity for selected cycle numbers from the same test. (c) $\mathrm{d} Q / \mathrm{d} V \mathrm{plots}$ for cycles $1,2,3$ and 5 for the same test. 
capacity of $211 \mathrm{~mA} \mathrm{~h} \mathrm{~g}^{-1}$, corresponding to a CE of $61 \%$ for the first cycle. This demonstrates a greater extent of potassium insertion into graphite with higher reversibility than for PG. A jump in charge capacity to $220 \mathrm{~mA} \mathrm{~h} \mathrm{~g}{ }^{-1}$ is observed for the second cycle, and, upon further cycling, discharge capacities higher than 150 and $100 \mathrm{~mA} \mathrm{~h} \mathrm{~g}^{-1}$ are achieved after 100 and 200 cycles, respectively. Moreover, a CE of $88 \%$ is calculated for the second cycle, which then soon yields values of $\geq 95 \%$. Fig. $3 \mathrm{~b}$ shows the electrochemical performance of the BMG at a higher current density of $250 \mathrm{~mA} \mathrm{~g}^{-1}$, corresponding to a Crate of $\sim \mathrm{C} / 1.1$. Accordingly, the BMG electrode cycled at this Crate shows initial promising behaviour with a charge capacity of $209 \mathrm{~mA} \mathrm{~h} \mathrm{~g}^{-1}$ in the second cycle and CE values higher than $90 \%$ for 50 cycles. Nevertheless, the capacity fade on extended cycling is evident, yielding only a $36 \%$ capacity retention after 50 cycles and $12 \%$ after 100 cycles. The voltage profile for the first discharge in Fig. 3c appears very similar to that for the PG electrode, with a number of plateaux corresponding to SEI formation and potassium insertion. This is evident also from $\mathrm{d} Q / \mathrm{d} V$ plots (Fig. $3 \mathrm{~d}$ ) which confirm similar processes occurring for both the BMG and PG. Cyclic voltammetry measurements (Fig. S3 $\dagger$ ) complement $\mathrm{d} Q / \mathrm{d} V$ plots showing peaks at between 1.10 and $0.60 \mathrm{~V}$ corresponding to SEI formation, together with a prominent feature at $0.40-0.01 \mathrm{~V}$ corresponding to potassium insertion into graphite. SEI formation is confirmed to mainly occur only during the first cycle, since in subsequent cycles, only the intercalation peak is detected during reduction.

These results demonstrate a rather high electrochemical reversibility of the BMG and clearly demonstrate the role of the ball-milling process, which enables close to the theoretical capacities and only a moderate capacity fade upon prolonged cycling. Extensive SEI formation appears to occur mainly during the first discharge, after which the insertion/extraction mechanism is seen to be reasonably reversible.

The stability and evolution of the SEI was studied by means of galvanostatic pause tests, as shown in Fig. 4, subjecting the BMG electrode to alternating periods of galvanostatic cycling and open-circuit voltage (OCV) measurements..$^{22}$ Comparing the discharge capacities of the cycles before and after the pauses allows for the investigation of SEI behaviour during the OCV period. A decrease in the discharge capacity implies a continued spontaneous passivation of the electrode surface during the OCV period, whereas an increase indicates the dissolution of the SEI into the electrolyte and consequent reformation of the SEI. Discharge capacities of 205 and $195 \mathrm{~mA} \mathrm{~h} \mathrm{~g}^{-1}(-4.9 \%)$ are measured at the $6^{\text {th }}$ and $7^{\text {th }}$ cycles, before and after the first pause of four days, indicating that a spontaneous passivation
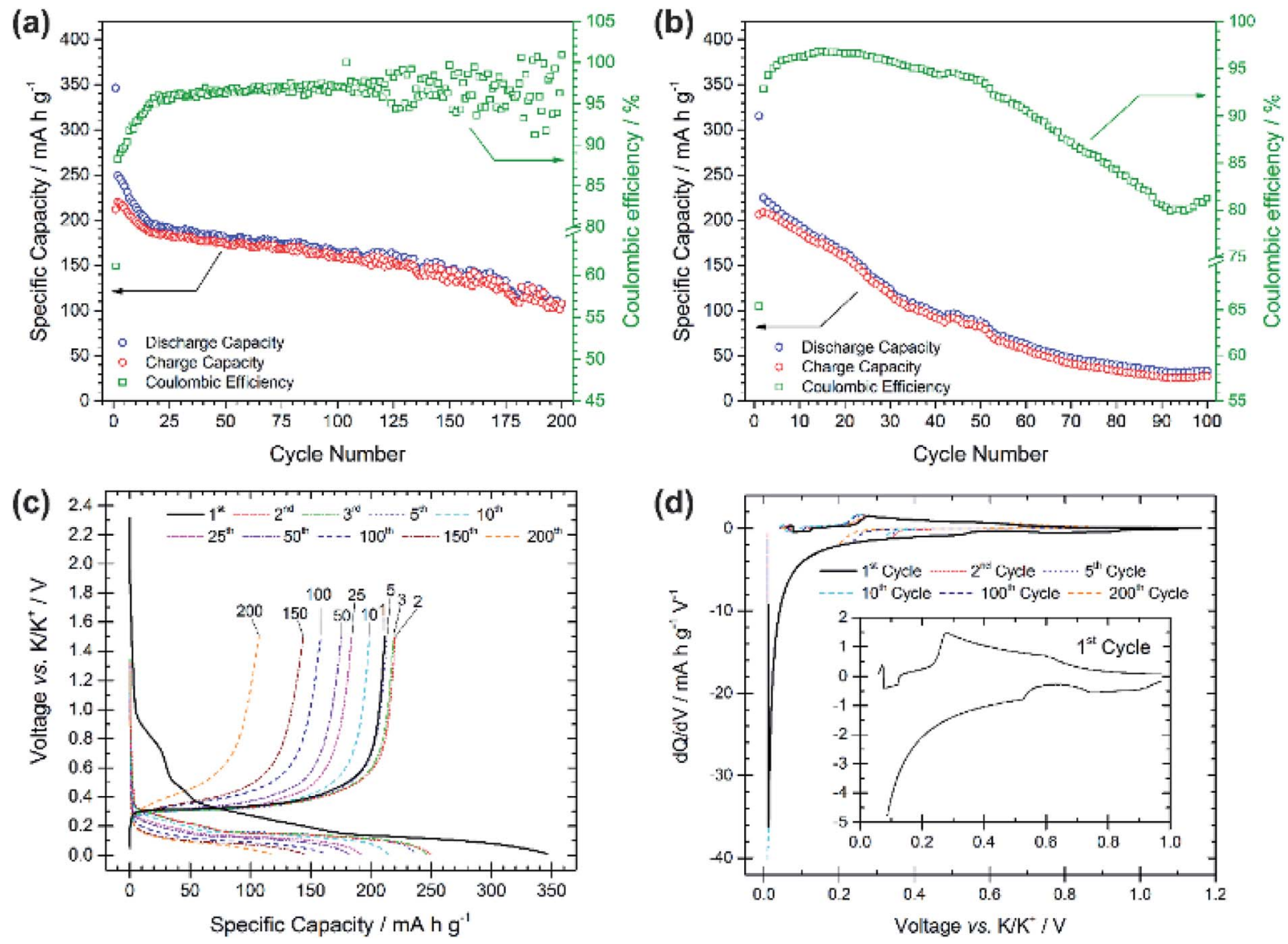

Fig. 3 Specific capacity vs. cycle number for the ball-milled graphite (BMG) electrode galvanostatically cycled at (a) $25 \mathrm{~mA}^{-1}$ and (b) $250 \mathrm{~mA} \mathrm{~g}^{-1}$ with potential limitations of $0.01 \mathrm{~V}$ and $1.5 \mathrm{~V} \mathrm{vs}$. $\mathrm{K} / \mathrm{K}^{+}$. (c) Voltage profiles vs. specific capacity for selected cycle numbers from the test at $25 \mathrm{~mA} \mathrm{~g}^{-1}$. (d) dQ/dV plots for cycles 1, 2, 5, 10, 100, and 200 from the test at $25 \mathrm{~mA} \mathrm{~g}^{-1}$. 

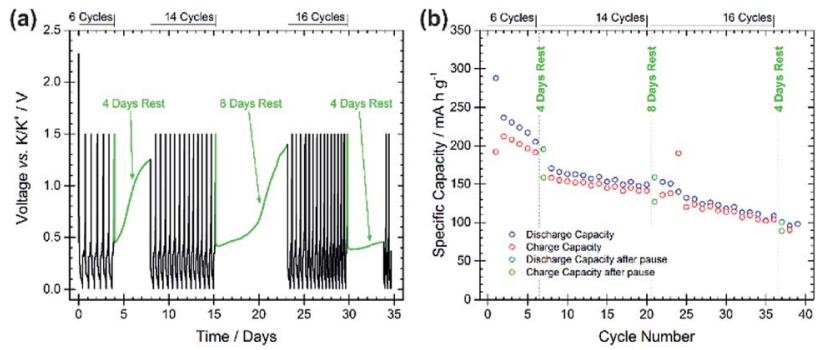

Fig. 4 (a) Voltage profile of a pause test at $25 \mathrm{~mA} \mathrm{~g}^{-1}$ using BMG as the working electrode. Potential limitations of $0.01 \mathrm{~V}$ and $1.5 \mathrm{~V} v \mathrm{vs} . \mathrm{K} / \mathrm{K}^{+}$ were used with the following cycling regime: 6 cycles, rest 4 days, 14 cycles, rest 8 days, 16 cycles, rest 4 days, continued cycling. (b) Specific capacity for galvanostatic discharge/charge cycles during the pause test.

effectively occurred. This is in agreement with the typically large capacity decay observed in the first cycles for the BMG electrode. The rapid capacity fade can be attributed to continued passivation of the electrode surface. Discharge capacities of 149 and $159 \mathrm{~mA} \mathrm{~h} \mathrm{~g}^{-1}(+6.7 \%)$ were recorded before and after the second pause, and 108 and $101 \mathrm{~mA} \mathrm{~h} \mathrm{~g}^{-1}(-6.5 \%)$ before and after the third pause. The increase in capacity after the second pause suggests that some dissolution of the SEI has occurred during the rest, which is being reformed on the subsequent discharge. However, the decrease after the third pause indicates still continued SEI formation even in later cycles.

\section{Conclusions}

Overall, we have demonstrated the key role that ball-mill processing has upon the electrochemical performance of graphite anodes in potassium-ion half-cells. High specific capacities of more than $200 \mathrm{~mA} \mathrm{~h} \mathrm{~g}^{-1}$ are reported after 10 cycles, at which point the as-received graphite had already lost $50 \%$ of its initial capacity. Subsequent extended cycling beyond 200 cycles is achieved with coulombic efficiencies reaching on average $98 \%$. This substantially improved performance of the ball-milled graphite is explained through SEM and Raman analyses, which confirm a gentle mechanical exfoliation of the graphene layers with concomitant formation of structural defects. The high stability of the potassium metal counter electrode has been verified in half-cells, yet with some instability or continued growth of the SEI on these graphite electrodes, as indicated by electrochemical pause tests. Graphite ball-milling should therefore be employed as a standard method for fabricating these potassium-ion anodes, in order to provide enhanced performances.

\section{Conflicts of interest}

There are no conflicts to declare.

\section{Acknowledgements}

S. Renault and H. Eriksson are acknowledged for valuable discussions and technical help, respectively. M. Valvo gratefully acknowledges the support from the Swedish Energy Agency via the grant no. 2017-013531 and ÅForsk Foundation via the grant no. 18-317. R. Younesi would like to acknowledge the financial support by the Swedish Energy Agency ("Batterifondens" research program: TriLi project) and StandUp for Energy.

\section{Notes and references}

1 X. Wu, D. P. Leonard and X. Ji, Chem. Mater., 2017, 29, 50315042 .

2 C. Vaalma, D. Buchholz and S. Passerini, Curr. Opin. Electrochem., 2018, 9, 41-48.

3 Y. Li, R. A. Adams, A. Arora, V. G. Pol, A. M. Levine, R. J. Lee, K. Akato, A. K. Naskar and M. P. Paranthaman, J. Electrochem. Soc., 2017, 164, A1234-A1238.

4 S. Komaba, T. Hasegawa, M. Dahbi and K. Kubota, Electrochem. Commun., 2015, 60, 172-175.

5 Z. Jian, W. Luo and X. Ji, J. Am. Chem. Soc., 2015, 137, 1156611569.

6 J. Han, M. Xu, Y. Niu, G. N. Li, M. Wang, Y. Zhang, M. Jia and C. ming Li, Chem. Commun., 2016, 52, 11274-11276.

7 N. Recham, G. Rousse, M. T. Sougrati, J. N. Chotard, C. Frayret, S. Mariyappan, B. C. Melot, J. C. Jumas and J. M. Tarascon, Chem. Mater., 2012, 24, 4363-4370.

8 J. C. Pramudita, D. Sehrawat, D. Goonetilleke and N. Sharma, Adv. Energy Mater., 2017, 7, 1602911.

9 A. P. Cohn, N. Muralidharan, R. Carter, K. Share, L. Oakes and C. L. Pint, J. Mater. Chem. A, 2016, 4, 14954-14959.

10 J. Zhao, X. Zou, Y. Zhu, Y. Xu and C. Wang, Adv. Funct. Mater., 2016, 26, 8103-8110.

11 W. Luo, J. Wan, B. Ozdemir, W. Bao, Y. Chen, J. Dai, H. Lin, Y. Xu, F. Gu, V. Barone and L. Hu, Nano Lett., 2015, 15, 76717677.

12 L. Xue, Y. Li, H. Gao, W. Zhou, X. Lü, W. Kaveevivitchai, A. Manthiram and J. B. Goodenough, J. Am. Chem. Soc., 2017, 139, 2164-2167.

13 L. M. Malard, M. A. Pimenta, G. Dresselhaus and M. S. Dresselhaus, Phys. Rep., 2009, 473, 51-87.

14 A. C. Ferrari, Solid State Commun., 2007, 143, 47-57.

15 A. C. Ferrari and J. Robertson, Phys. Rev. B: Condens. Matter Mater. Phys., 2000, 61, 14095-14107.

16 F. Tuinstra and J. L. Koenig, J. Chem. Phys., 1970, 53, 11261130.

17 R. J. Nemanich and S. A. Solin, Phys. Rev. B: Condens. Matter Mater. Phys., 1979, 20, 392-401.

18 E. Björklund, D. Brandell, M. Hahlin, K. Edström and R. Younesi, J. Electrochem. Soc., 2017, 164, A3054-A3059.

19 C. Liu, M. Carboni, W. R. Brant, R. Pan, J. Hedman, J. Zhu, T. Gustafsson and R. Younesi, ACS Appl. Mater. Interfaces, 2018, 10, 13534.

20 D. I. Iermakova, R. Dugas, M. R. Palacín and A. Ponrouch, J. Electrochem. Soc., 2015, 162, A7060-A7066.

21 R. Younesi and F. Bardé, Sci. Rep., 2017, 7, 15925.

22 R. Mogensen, D. Brandell and R. Younesi, ACS Energy Lett., 2016, 1, 1173-1178. 